\title{
Current use and timing of spinal surgery for management of acute spinal cord injury in North America: results of a retrospective multicenter study
}

\author{
Charles H. Tator, M.D., Ph.D., Michael Fehlings, M.D., Ph.D., Kevin Thorpe, M.Math., and \\ Wayne Taylor, M.A.
}

Division of Neurosurgery and Spinal Program, Toronto Hospital and University of Toronto, Toronto, Ontario, Canada; and Department of Clinical Epidemiology and Biostatistics, McMaster University, Hamilton, Ontario, Canada

A multicenter retrospective study was performed in 36 participating North American centers to examine the use and timing of surgery in the treatment of acute spinal cord injury (SCI). The study was conducted to obtain information required for the planning of a randomized controlled trial of early compared with late decompressive surgery.

The records of all patients aged 16 to 75 years with acute SCI who were admitted to the 36 centers within 24 hours of injury over a 9-month period (August 1994 to April 1995) were examined to obtain data on admission variables, methods of diagnosis, use of traction, and surgical variables including type and timing of surgery.

A total of 585 patients with acute SCI or cauda equina injury were admitted to these centers, although approximately half were ultimately excluded because they did not meet inclusion criteria. Common causes for exclusion were late admission, age, gunshot wound, and an absence of spinal cord compression demonstrated on imaging studies. Thus, only approximately $50 \%$ of acute SCI patients would be eligible for inclusion in a study of acute decompressive procedures. Although $100 \%$ of patient underwent computerized tomography (CT) scaning, only 54\% underwent magnetic resonance imaging, and CT myelography was performed in only 6\%. Complete neurological injuries (American Spinal Injury Association Grade A) were present in 57.8\%. Traction was applied in only $47 \%$ of patients with cervical injuries, of which only $42 \%$ demonstrated successful decompression by traction. Neurological deterioration occurred in $8.1 \%$ of patients after traction. Surgery was performed in $65.4 \%$ of patients. The timing of surgery varied widely: less than 24 hours in $23.5 \%$ of patients; 25 to 48 hours in $15.8 \%$; 48 to 96 hours in $19.0 \%$; and 5 days or longer in $41.7 \%$ of patients.

These data indicate that whereas surgery is commonly performed in patients with acute SCI, one-third of the cases are managed nonoperatively, and there is very little agreement on the optimum timing of surgical treatment. The results of this study confirm the need for a randomized controlled trial to 
determine the optimum timing of surgical decompressive procedures in patients with SCI.

Key Words * acute spinal cord injury * timing of surgery * multicenter clinical study

The Surgical Treatment for Acute Spinal Cord Injury Study (STASCIS) group was formed in 1992 by the Spinal Cord Injury Committee of the Joint Section on Neurotrauma and Critical Care of the American Association of Neurological Surgeons (AANS) and the Congress of Neurological Surgeons (CNS), the two largest neurosurgical specialty organizations in North America. In 1996, STASCIS was joined by the Joint Section on Spinal Disorders and Peripheral Nerves of the AANS/CNS. The principal aim of the STASCIS group was to conduct a randomized prospective controlled trial to examine the role and timing of decompressive surgery performed on the spinal cord and cauda equina of patients after acute spinal injury.

In the present paper we describe the methodology and results of the first STASCIS study, the aim of which was to assess in a retrospective study the use and timing of spinal surgery to treat patients with acute SCI in North America. This information was sought by the STASCIS group to design a protocol for a randomized, prospective trial of surgical decompression for acute SCI. The study was conducted in 1994 and 1995 among 36 North American centers. Although numerous individual surgical series were available from the literature,[5,34,35,38,45,51] very few studies provided an overall analysis of the use and timing of surgery in acute SCI in more than one center, especially with respect to surgical decompressive procedures. Exceptions to this were the National Acute Spinal Cord Injury Study-1 (NASCIS-1) and NASCIS-2[10,11,12] trials, which provided some information on the use of surgery, although important issues such as the exact type of surgery performed were omitted.[26]

\section{CLINICAL MATERIAL AND METHOD}

\section{Clinical Coordinating and Statistical Centers}

The clinical coordinating center for this study was the Division of Neurosurgery at the Toronto Hospital, University of Toronto, Toronto, Ontario, and the statistical center was the Department of Clinical Epidemiology and Biostatistics, McMaster University, Hamilton, Ontario, Canada. Specific reporting forms were developed for the recording of individual patient data.

\section{Participating Investigators and Participating Centers}

Through advertisements in the AANS and CNS newsletters and through membership in the Spinal Cord Injury Committee, 36 of the major SCI centers in North America were recruited into the study (Table 1), including 33 U.S. centers and three Canadian centers. There was a very wide representative geographic distribution, as well as a mixture of teaching and nonteaching hospitals. 


\begin{tabular}{|c|c|c|c|c|}
\hline $\begin{array}{l}\text { Certer } \\
\text { No. }\end{array}$ & Paticipating Certer & $\begin{array}{l}\text { Parlici pating } \\
\text { Irrestigat or }\end{array}$ & $\begin{array}{l}\text { No. of } \\
\text { Cases }\end{array}$ & $\begin{array}{l}\text { Mean } \\
\text { Age } \\
(y+s)\end{array}$ \\
\hline 1 & Uni versity of Alabama, Eirmingham, AL & M Hadley & 10 & 37 \\
\hline 2 & Saint Joseph's Hospital, Phoenix, AZ & CDickman, V Sonntag & 4 & 30 \\
\hline 3 & Drew Uni versity, Los Angeles, CÁ & G Locke & 6 & 31 \\
\hline 4 & Uni versity of California, Davis, Sacramento, CA & F idagner & 10 & 30 \\
\hline 5 & Uni versity of California, San Diego, San Diego, CA & L Marshall & 20 & 32 \\
\hline 6 & Hartford Hospitals, Hartford, CT & $\mathrm{H}$ Onyiuke & 16 & 44 \\
\hline 7 & Uni versity of Florida, Jackson ville, FL & C Aroe, 'W' Faillace & 17 & 46 \\
\hline 8 & Uni versity of Miami School of Medicine, Miami, FL & B Green, P Madsen & 34 & 42 \\
\hline 9 & Orando Regional Medical Oenter, Orlando, FL & D Behrmann & 14 & 40 \\
\hline 10 & Neurological Institute of Savannah PC, Savannah, GA & F intrirth & 13 & 34 \\
\hline 11 & Indiana University Medical Center,Indianapolis, IN & C Shapiro & 10 & 38 \\
\hline 12 & Uni versity of loma, lowa City, IA & P Hitchon, V Traynelis & 14 & 43 \\
\hline 13 & Uni versity of Kansas Medical Center, Kansas City, KS & P Arnold & 15 & 35 \\
\hline 14 & Henry Ford Hospital, Detroit, Ml & R Nockels & 14 & 41 \\
\hline 15 & Cooper Hospitaluni versity Medical Center, Cam den, NJ & $S$ Neff & 42 & 35 \\
\hline 16 & Uni versity of New Mexio, Albuquerque, NM & E Benzel, Á Halliday & 8 & 44 \\
\hline 17 & Mount Sinaj Medical Center, New York, NY & N Perin & 7 & 35 \\
\hline 18 & State Uni versity of New York, Syracuse, NY & R Martin & 5 & 48 \\
\hline 19 & Victoria General Hospital, Halifax, NS & R Holness & 14 & 40 \\
\hline 20 & McMaster University, Hamil ton, ON & K Reddy & 19 & 49 \\
\hline 21 & Sunnytrook Heal th Sciences Center, Toronto, ON & M Fazl & 12 & 40 \\
\hline 22 & The Toronto Hospital, Toronto, ON & C Tator, M Fehlings & 14 & 46 \\
\hline 23 & Oregon Heal th Sciences Center, Portland, $O R$ & F Edmund & 21 & 38 \\
\hline 24 & Temple Uni wersity School of Medicine, Philadel phia, PÁ & R Narayan, 'W' Young & 11 & 51 \\
\hline 25 & Thomas Jefferson Uni wersity Philadel phia, PA & B Northrup & 104 & 45 \\
\hline 26 & Uni versity of Philadelphia, Philadel phia, PÁ & P Mlarcotte & 7 & 40 \\
\hline 27 & Älegheny General Hospital, Pittsburgh, PA & J 'villterger & 10 & 38 \\
\hline 28 & Presbyterian Uni versity Hospital, Pittsbungh, PA & D Marion & 9 & 36 \\
\hline 29 & Rhode Isand Hospital, Providence, RI & F Harrington & 15 & 40 \\
\hline 30 & Plains UC \& Regina General Hospital, Regina, SK & CEkong & 12 & 45 \\
\hline 31 & Medical Uni versity of South Carolina, Charleston, SC & B cuddy & 20 & 31 \\
\hline 32 & Center for Neurological Disorders, PA, Ft inorth, TX & G Cravens & 9 & 45 \\
\hline 33 & Ben Taub General Hospital, Houston, TX & Á Valadka & 15 & 34 \\
\hline 34 & Fairfax Hospital, Falls Church, VA & J Burgess & 12 & 39 \\
\hline 35 & Medical College of Virginia, Richm ond, VA & K Holloway & 9 & 48 \\
\hline \multirow[t]{2}{*}{36} & Froedtert Memorial Lutheran Hospital, Mil maukee, 'Mill & D Maiman, J Hollowell & 13 & 36 \\
\hline & & total & 585 & 40 \\
\hline
\end{tabular}

\section{Protocol Format}

The participating investigators were asked in the fall of 1995 to record retrospectively the information on all patients with spinal cord or cauda equina injuries who were admitted to their centers within 24 hours of injury during the 9 month trial period (August 1994 to April 1995). Specific questions were posed to determine whether the patients would have been eligible for a planned trial of decompressive surgery according to a specific protocol that had been developed by STASCIS. This protocol would theoretically include all patients with spinal cord or cauda equina injury at all levels of the vertebral column, both neurologically complete (American Spinal Injury Associtation [ASIA] A) and incomplete (ASIA B-D) injuries. Investigators were asked to evaluate whether the obtained data on each patient would have conformed to a specific list of inclusion criteria (Table 2) which were almost identical to those used in the previous NASCIS protocols with respect to age, medical risk factors, and other variables,[10-12] and to "predict" retrospectively whether each patient would have been able to provide consent. In this way, 
we attempted to evaluate the features of the planned protocol for a randomized, prospective trial.

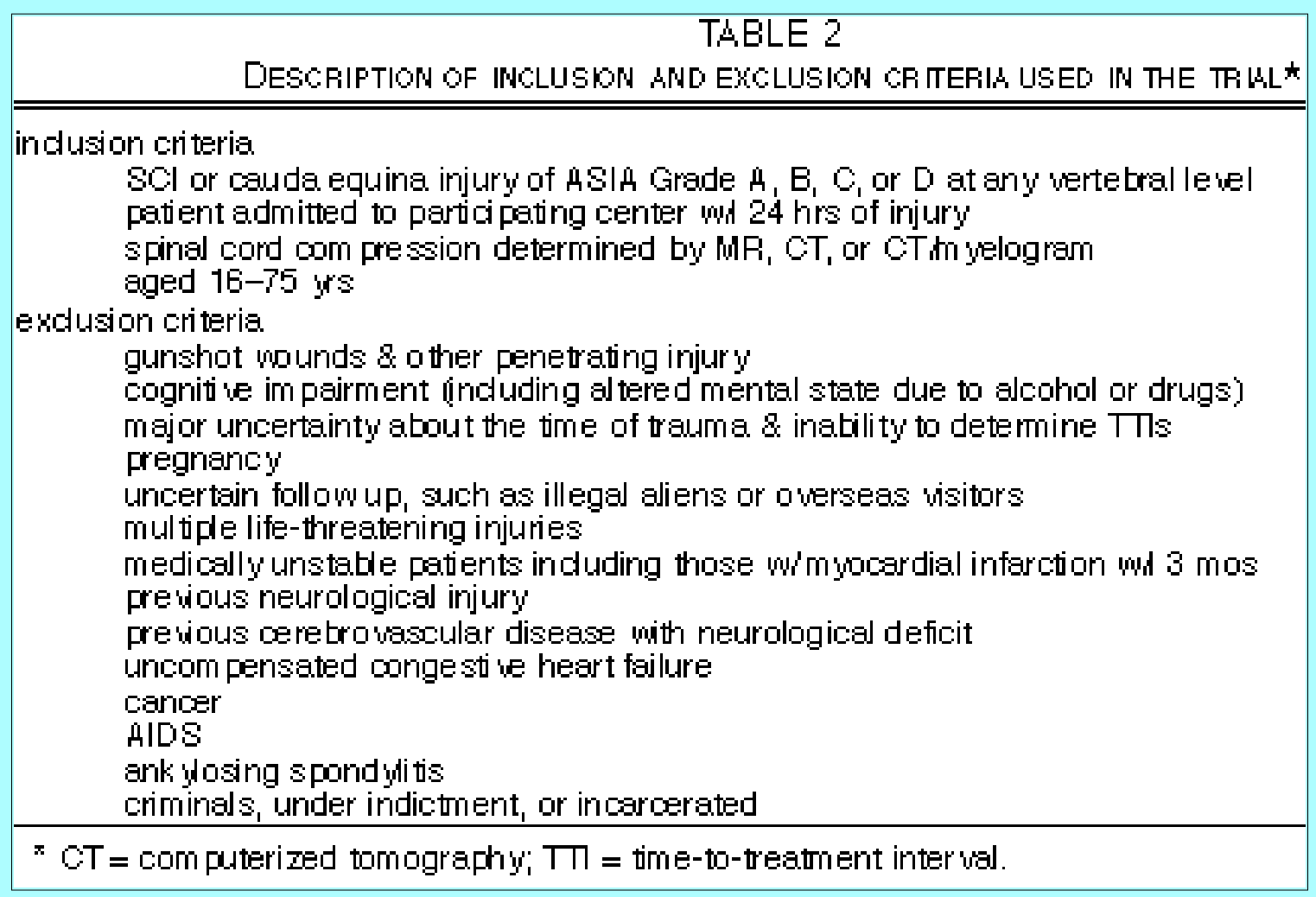

\section{RESULTS}

\section{Number of Cases and Age of Patients}

Table 1 shows that 585 patients with acute SCI or cauda equina injury were admitted to the 36 centers during the 9 month study interval. The maximum number of patients admitted to a single center was 104 and the minimum was four. The overall mean age was 40 years.

\section{Vertebral Level of Injury}

Overall, $64.5 \%$ of the injuries were cervical (C1 to $\mathrm{C} 7-\mathrm{T} 1), 18.7 \%$ were thoracic (T1-11), $11.0 \%$ were thoracolumbar (T11-12 to L1-2), and 5.8\% were lumbosacral (L2-S5) (Table 3). In some centers there was a much higher incidence of cervical injuries, most likely due to the greater involvement of orthopedic spinal surgeons in those centers who had more responsibility for managing patients with noncervical injuries. 
Vertebral Level and Sever TY of InJuRV (ASIA Griade) and Method of IMaging*

\begin{tabular}{|c|c|c|c|c|c|c|c|c|c|c|c|}
\hline \multirow{3}{*}{$\begin{array}{c}\text { Certer } \\
N_{0} .\end{array}$} & \multicolumn{4}{|c|}{ Level of Injury } & \multirow{2}{*}{\multicolumn{4}{|c|}{ ASAGrade }} & \multirow{2}{*}{\multicolumn{3}{|c|}{ Imaging Study }} \\
\hline & \multirow{2}{*}{$\begin{array}{l}\text { Cer- } \\
\text { vical }\end{array}$} & \multirow{2}{*}{$\begin{array}{l}\text { Tho- } \\
\text { racic }\end{array}$} & \multirow{2}{*}{$\begin{array}{l}\text { Thorac:0- } \\
\text { lumbar }\end{array}$} & \multirow{2}{*}{$\begin{array}{l}\text { Lumbo- } \\
\text { sacral }\end{array}$} & & & & & & & \\
\hline & & & & & $A$ & $\mathrm{~B}$ & $\mathrm{C}$ & $\mathrm{D}$ & $\mathrm{CT}$ & CTM & MR \\
\hline 1 & 10 & 0 & 0 & 0 & 4 & 2 & 3 & 1 & 10 & 0 & 10 \\
\hline 2 & 3 & 0 & 1 & 0 & 4 & 0 & 0 & 0 & 4 & 0 & 3 \\
\hline 3 & 6 & 0 & 0 & 0 & 4 & 0 & 0 & 2 & 3 & 0 & 2 \\
\hline 4 & 8 & 2 & 0 & 0 & 8 & 0 & 1 & 1 & 9 & 0 & 6 \\
\hline 5 & 12 & 5 & 2 & 1 & 8 & 0 & 8 & 4 & 18 & 0 & 6 \\
\hline 6 & 9 & 4 & 2 & 1 & 7 & 6 & 3 & 0 & 15 & 0 & 8 \\
\hline 7 & 10 & 4 & $\overline{3}$ & 0 & 10 & 0 & 4 & 3 & 15 & 4 & 4 \\
\hline 8 & 18 & 14 & 2 & 0 & 21 & 4 & 7 & 2 & 34 & 1 & 19 \\
\hline 9 & 13 & 1 & 0 & 0 & 7 & 4 & 0 & $\overline{3}$ & 10 & 0 & 10 \\
\hline 10 & 6 & 4 & 2 & 1 & 7 & 4 & 1 & 1 & 12 & 1 & 2 \\
\hline 11 & 7 & 1 & 1 & 1 & 1 & 1 & 0 & 8 & 10 & 0 & 10 \\
\hline 12 & 6 & 3 & 2 & 3 & 5 & 0 & 5 & 4 & 13 & 0 & 13 \\
\hline 13 & 8 & 3 & $\overline{3}$ & 1 & 6 & 0 & 3 & 6 & 15 & 0 & 15 \\
\hline 14 & 11 & 1 & 1 & 1 & 7 & 0 & 3 & 4 & 13 & 4 & 10 \\
\hline 15 & 24 & 5 & 2 & 1 & 8 & 2 & 17 & 15 & 42 & 5 & 26 \\
\hline 16 & 1 & 2 & 4 & 1 & 2 & 2 & 0 & 3 & 8 & 0 & 1 \\
\hline 17 & 16 & 1 & 0 & 0 & 2 & 2 & 0 & 3 & 7 & 1 & 2 \\
\hline 18 & 3 & 0 & 1 & 1 & 2 & 0 & 1 & 2 & 5 & 0 & $\overline{0}$ \\
\hline 19 & 10 & 1 & 3 & 0 & 7 & 1 & 1 & 5 & 8 & 2 & 3 \\
\hline 20 & 9 & 5 & 5 & 0 & 6 & 8 & 4 & 1 & 18 & 3 & 1 \\
\hline 21 & 5 & 1 & 2 & 4 & 1 & 1 & 4 & 6 & 11 & 0 & 4 \\
\hline 22 & 12 & 2 & 0 & 0 & 6 & 2 & 4 & 2 & 14 & 1 & 14 \\
\hline 23 & 14 & 2 & 3 & 2 & 8 & 0 & 3 & 10 & 17 & 0 & 4 \\
\hline 24 & 10 & 0 & 0 & 1 & 1 & 0 & 4 & 6 & 11 & 0 & 11 \\
\hline 25 & 69 & 17 & 12 & 6 & 42 & 10 & 27 & 25 & 70 & 1 & 66 \\
\hline 26 & 4 & 3 & 0 & 0 & 6 & 1 & 0 & 0 & 7 & 0 & 2 \\
\hline 27 & 4 & 2 & 4 & 0 & 7 & 0 & 0 & 3 & 10 & 0 & 10 \\
\hline 28 & 5 & 4 & 0 & 0 & 6 & 0 & 0 & 3 & 8 & 0 & 6 \\
\hline 29 & 13 & 1 & 1 & 0 & 3 & 3 & 4 & 5 & 11 & 4 & 10 \\
\hline 30 & 10 & 0 & 0 & 2 & 5 & 0 & 6 & 1 & 6 & 4 & 0 \\
\hline 31 & 11 & 4 & 1 & 2 & 9 & 0 & 3 & 8 & 11 & 3 & 3 \\
\hline 32 & 5 & 1 & 3 & 0 & 1 & 1 & 4 & 3 & 8 & 0 & 7 \\
\hline 33 & 12 & 0 & 2 & 1 & 6 & 2 & 2 & 5 & 14 & 1 & 5 \\
\hline 34 & 4 & 6 & 1 & 1 & 7 & 0 & 2 & 3 & 12 & 0 & 4 \\
\hline 35 & 6 & 2 & 0 & 1 & 4 & 1 & 3 & 1 & 3 & 0 & 9 \\
\hline 36 & 5 & 6 & 0 & 0 & 9 & 0 & 4 & 0 & 12 & 0 & 10 \\
\hline total & 369 & 107 & 63 & 33 & 247 & 57 & 131 & 149 & 494 & 35 & 316 \\
\hline
\end{tabular}

\section{Severity of Neurological Injury}

Based on the ASIA neurological grading system,[2] 42.2\% of the injures were Grade A, or complete SCI, 9.7\% were Grade B, 22.6\% were Grade C, and $25.5 \%$ were Grade 4 (Table 3). In general, the distribution of ASIA grades was similar among the various centers, although some appeared to admit an unusually high percentage of Grade A injuries, whereas other centers admitted a higher percentage of patients with neurologically incomplete injuries.

\section{Inclusion and Exclusion Criteria}

Based on the inclusion and exclusion criteria shown in Table 2, 62.1\% of the 550 cases for whom this information was available met the inclusion criteria on admission and would have been eligible for 
consideration for the planned study, whereas $37.1 \%$ would have been excluded (Table 4). The most frequent reasons for exclusion from the study were admission more than 24 hours postinjury, age, and the presence of gunshot wounds (Table 4). Absence of spinal cord compression, as determined by evaluation of available imaging studies on admission, would have excluded 18 patients, and presence of a concomitant head injury would have lead to exclusion of another 18 patients. It should be noted that absence of spinal cord compression based on imaging studies performed after admission resulted in the exclusion of many additional patients at a later stage.

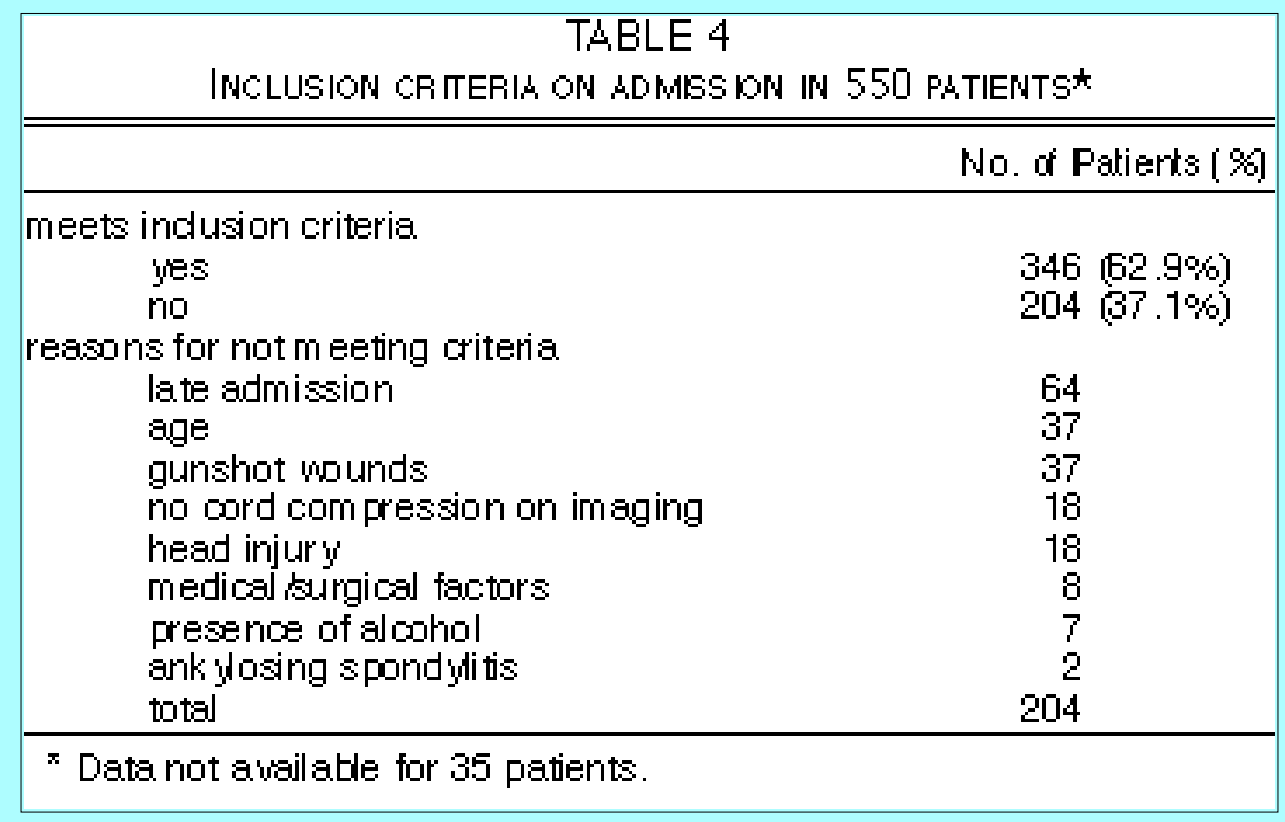

\section{Provision of Consent}

It was the opinion of the staff of the participating centers that $510(89.8 \%)$ of the 568 patients for whom this information was available would have been able to provide consent with respect to participation in the study, whereas 58 patients $(10.2 \%)$ would not have been able to provide consent. These latter patients included those with head injuries, excess levels of alcohol, and other factors.

\section{Imaging Studies}

Although $100 \%$ of the patients underwent computerized tomography scanning, only $54 \%$ underwent magnetic resonance (MR) imaging (Table 3). As expected, computerized tomography myelograms were infrequently obtained (6\%). The use of MR imaging varied significantly among centers, with some performing MR imaging in $90 \%$ or more of cases, whereas others performed it in only 10 to $20 \%$ of cases.

\section{Overall Inclusion Rate Based on Imaging and Admission Eligibility}

Data obtained from imaging studies performed prior to traction were available regarding the presence of spinal cord compression or deformation in 459 patients; in $303(66 \%)$ there was cord compression or deformation patients whereas in 156 (34\%) there was none. Thus, if the planned prospective study included only those patients who met all the inclusion criteria outlined in Table 2, and who were not excluded for any of the listed reasons for exclusion shown in Table 4 (omitting the 18 cases shown not to have cord compression on admission imaging studies and who would have been excluded on the basis of this finding), the eligibility rate would be $66 \%$. By multiplying the rate of imaging study-detected spinal cord compression $(66 \%)$ by the rate of potential eligibility $(66 \%)$, one can deduce an approximate overall 
inclusion rate of $44 \%$. It is likely that this figure is a slight underestimation of the true inclusion rate because some patients may have been excluded based on more than one criterion. Accordingly, we estimate a true inclusion rate of approximately $50 \%$ based on the available data in this study.

\section{Use of Traction}

There was information on the use of traction in 173 cases of cervical cord injury, and traction was applied in $47 \%$ of cases. In the opinion of the participating investigators, spinal cord deformation persisted after traction in $43 \%$ of cases in which it was applied. The participants reported neurological deterioration during traction in 14 patients $(8.1 \%)$. Information is not available regarding the severity of neurological deterioration and whether the deficits were temporary or permanent.

\section{Incidence, Type, and Timing of Surgical Treatment}

Information was requested on the use of surgical treatment in these 585 patients and information was available for 583 patients; $65.4 \%$ (381) underwent surgical treatment, and 34.6\% (202) did not. Decompressive surgery was performed in $68.2 \%$ of those receiving surgical treatment, whereas fusion was performed in $85.7 \%$. The majority of the patients underwent both decompressive surgery and spinal fusion. Data obtained on the timing of surgery were available for 374 of the 381 surgical cases. Surgery was performed at 24 hours or less postinjury in $23.5 \%$ (88) of patients, 25 to 48 hours postinjury in $15.8 \%$ (59), 48 to 96 hours postinjury in $19.0 \%$ (71) and 5 days or more postinjury in $41.7 \%$ (156) of patients (Table 5).

\begin{tabular}{|c|c|c|c|c|}
\hline \multicolumn{5}{|c|}{$\begin{array}{c}\text { TABLE } 5 \\
\text { TIME FROM TRAUMA TO SURGERV IN } 374 \text { PATIENTS }\end{array}$} \\
\hline & \multicolumn{4}{|c|}{ Timing of Surgery } \\
\hline & $<24 \mathrm{Hrs}$ & $25-48 \mathrm{Hrs}$ & $48-96 \mathrm{Hrs}$ & $>5$ Days \\
\hline no. of patients $(\%)$ & $88(23.5)$ & $59(15.8)$ & $71(19.0)$ & $156(41.7)$ \\
\hline
\end{tabular}

\section{DISCUSSION}

The epidemiological features of these patients--age, level and severity of injury and other admission variables--were similar to those reported in other SCI patient populations. $[31,32,41,44,46,48]$ For example, in this trial approximately two-thirds of the cases had sustained cervical injuries and approximately $60 \%$ were incomplete neurological injuries; these data are in keeping with other large series of SCI patients admitted to SCI units in North America in which neurosurgeons play a significant role.

This retrospective study was undertaken in attempt to define the feasibility of conducting a prospective randomized controlled trial of the timing and effectiveness of decompressive surgery of the spinal cord. Although pharmacotherapy using methylprednisolone has been proven to be effective in improving neurological deficits in patients with acute SCI, the results of the North American[12,13] and Japanese[40] trials in large numbers of patients have shown only a minimal amount of improvement. Modest neurological improvement was also seen when treating patients with GM-1 ganglioside in a trial in a small number of patients.[28] Thus, further studies of other drugs and other treatments must be undertaken to enhance the neurological recovery. There is evidence from experimental studies in laboratory models that early decompressive surgery improves neurological 
recovery.[8,15,17,19,21,23,30,33,39,41,42,43] For example, in the laboratory of one of the authors (C.H.T.), removal at 2 hours of an extradural clip that compressed the spinal cord produced better neurological recovery than removal at 4 hours.[30] In some clinical studies in patients who have undergone decompressive surgery, promising results have been demonstrated, $[6,53,54]$ although results of other studies have failed to show a benefit from early decompressive compared with later decompressive surgery.[5,26,34,35,38,49-51] Findings from several studies have failed to show improved recovery in those patients who underwent surgery compared with those receiving nonoperative treatment.[24,45,52] For example, in a study by one of the authors (C.H.T.), the outcome in 116 patients who underwent operative treatment (decompressive surgery in 75 , fusion in 41) was compared with the outcome in 92 who did not undergo surgery, and there was no difference in neurological recovery between the two groups.[45] However, it should be noted that, with one exception, none of these studies was a randomized controlled trial in which patients were allocated to surgical or nonsurgical groups or to early or late surgery. The exception was the study by Vaccaro, et al.,[49] reported in 1997, in which patients were randomly allocated to an early-surgery or late-surgery group. In this study, only a small number of patients were studied: the early-surgery group, defined as undergoing surgery within 72 hours of injury, contained 34 patients (mean time to surgery 1.8 days); and the late-surgery group, defined as undergoing surgery more than 5 days after injury, contained 28 patients (mean time to surgery 16.8 days). There was no difference in neurological outcome between the two groups. The other shortcoming in this study was the low rate of follow up (approximately one-third of the patients were lost to follow-up reviews).

The authors of several other studies have reported improved neurological outcome in patients who underwent late decompressive surgery days, weeks, or months postinjury, $[3,7,9,14,22,34,36]$ but none of these studies was a randomized controlled trial. Traction has also been reported to improve neurological outcome, especially if applied early, $[1,16,18,29]$ but none of these studies reporting on traction was a randomized controlled trial. However, the authors of several studies did not find any neurological benefit in patients who underwent spinal reduction procedures,[20,32,52] with the possible exception of patients who suffered bilateral facet dislocation.[4] Furthermore, early spinal reduction procedures performed prior to imaging studies have become controversial because neurological deterioration has been reported after traction primarily in patients with large disc herniations.[25,27] It should be noted that the present study demonstrated an $8 \%$ rate of neurological deterioration due to traction. Unfortunately, data are not available regarding the severity and permanence of these deficits.

In the present study, we found that approximately $66 \%$ of patients with acute SCI are undergoing surgical treatments, and as noted above, there is no definite proof that the treatment yields improved neurological recovery. It should be noted that many of the authors claim that surgery enhances early mobilization and reduces length of hospital stay, but there is no definite proof. Furthermore, the effect of surgery, especially early surgery, on the rate of complications such as pneumonia or deep venous thrombosis is controversial.[37,55]

Findings from the present study showed a lack of consensus among centers concerning the optimum timing of surgical treatment, and only a minority of patients underwent surgery within 24 hours of trauma. Even this interval may be too late to reverse some of the secondary injury mechanisms identified after SCI.[47] The only therapeutic window established in humans is the 8-hour trauma-to-treatment window reported in the NASCIS-2 study in which methylprednisolone was used.[12]

We have shown that only approximately $50 \%$ of patients currently admitted to spinal cord centers in 
North America would be eligible for inclusion in a randomized controlled trial of early compared with late decompression performed by using traction or surgery. This was based on inclusion of only those patients admitted within 24 hours of trauma. Thus, a randomized trial to study early decompressive surgery at a shorter therapeutic window time, such as 8 hours based on the NASCIS- 2 results, would require a public education campaign and specific instructions to first aid personnel and emergency physicians to encourage much earlier referral to spinal cord treatment centers.

\section{Acknowledgment}

The authors are grateful to Sandi Amaral for her assistance in manuscript preparation.

\section{References}

1. 1. Aebi M, Mohler J, Zach GA, et al: Indication, surgical technique, and results of 100 surgically-treated fractures and fracture-dislocations of the cervical spine. Clin Orthop 203:244-257, 1986

2. American Spinal Injury Association: Standards for Neurological and Functional Classification of Spinal Cord Injury. Revised Edition. Chicago, Ill: American Spinal Injury Association, 1992

3. Anderson PA, Bohlman HH: Anterior decompression and arthrodesis of the cervical spine: long-term motor improvement. Part II. Improvement in complete traumatic quadriplegia. J Bone Joint Surg (Am) 74:683-692, 1992

4. Bedbrook GM: Spinal injuries with tetraplegia and paraplegia. J Bone Joint Surg (Br) 61:267-284, 1979

5. Benzel EC, Larson SJ: Functional recovery after decompressive spine operation for cervical spine fractures. Neurosurgery 20:742-746, 1987

6. Benzel EC, Larson SJ: Recovery of nerve root function after complete quadriplegia from cervical spine fractures. Neurosurgery 19:809-812, 1986

7. Bohlman HH: Acute fractures and dislocations of the cervical spine. An analysis of three hundred hospitalized patients and review of the literature. J Bone Joint Surg (Am) 61:1119-1142, 1979

8. Bohlman HH, Bahniuk E, Raskulinecz G, et al: Mechanical factors affecting recovery from incomplete cervical spinal cord injury: a preliminary report. Johns Hopkins Med J 145:115-125, 1979

9. Bohlman HH, Freehafer A: Late anterior decompression of spinal cord injuries. J Bone Joint Surg (Am) 57:1025, 1979 (Abstract)

10. Bracken MB, Collins WF, Freeman DF, et al: Efficacy of methylprednisolone in acute spinal cord injury. JAMA 251:45-52, 1984

11. Bracken MB, Holford TR: Effects of timing of methylprednisolone or naloxone administration on recovery of segmental and-long tract neurological function in NASCIS 2. J Neurosurg 79:500-507, 1993

12. Bracken MB, Shepard MJ, Collins WF, et al: A randomized controlled trial of methylprednisolone or naloxone in the treatment of acute spinal cord injury. Results of the Second National Acute Spinal Cord 
Injury Study. N Engl J Med 322:1405-1411, 1990

13. Bracken MB, Shepard MJ, Holford TR, et al: Administration of methylprednisolone for 24 or 48 hours or tirilazad mesylate for 48 hours in the treatment of acute spinal cord injury. Results of the Third National Acute Spinal Cord Injury Randomized Controlled Trial. JAMA 277:1597-1604, 1997

14. Brodkey JS, Miller CF Jr, Harmody RM: The syndrome of acute central cervical spinal cord injury revisited. Surg Neurol 14:251-257, 1980

15. Brodkey JS, Richards DE, Blasingame JP, et al: Reversible spinal cord trauma in cats. Additive effects of direct pressure and ischemia. J Neurosurg 37:591-593, 1972

16. Brunette DD, Rockswold GL: Neurologic recovery following rapid spinal realignment for complete cervical spinal cord injury. J Trauma 27:445-447, 1987

17. Carlson GD, Warden KE, Barbeau JM, et al: Viscoelastic relaxation and regional blood flow response to spinal cord compression and decompression. Spine 22:1285-1291, 1997

18. Cotler JM, Herbison GJ, Nasuti JF, et al: Closed reduction of traumatic cervical spine dislocation using traction weights up to 140 pounds. Spine 18:386-390, 1993

19. Croft TJ, Brodkey JS, Nulsen FE: Reversible spinal cord trauma: a model for electrical monitoring of spinal cord function. J Neurosurg 36:402-406, 1972

20. Dall DM: Injuries of the cervical spine. II. Does anatomical reduction of the bony injuries improve the prognosis for spinal cord recovery? S Afr Med J 46:1083-1090, 1972

21. Delamarter RB, Sherman J, Carr JB: Pathophysiology of spinal cord injury. Recovery after immediate and delayed decompression. J Bone Joint Surg (Am) 77:1042-1049, 1995

22. Demopoulos HB, Flamm ES, Pietronigro DD, et al: The free radical pathology and the microcirculation in the major central nervous system disorders. Acta Physiol Scand Suppl 492:91-119, 1980

23. Dolan EJ, Tator CH, Endrenyi L: The value of decompression for acute experimental spinal cord compression injury. J Neurosurg 53:749-755, 1980

24. Donovan WH, Kopaniky D, Stolzmann E, et al: The neurological and skeletal outcome in patients with closed cervical spinal cord injury. J Neurosurg 66:690-694, 1987

25. Doran SE, Papadopoulos SM, Ducker TB, et al: Magnetic resonance imaging documentation of coexistent traumatic locked facets of the cervical spine and disc herniation. J Neurosurg 79:341-345, 1993

26. Duh MS, Shepard MJ, Wilberger JE, et al: The effectiveness of surgery on the treatment of acute spinal cord injury and its relation to pharmacological treatment. Neurosurgery 35:240-249, 1994

27. Eismont FJ, Arena MJ, Green BA: Extrusion of an intervertebral disc associated with traumatic subluxation or dislocation of cervical facets. Case report. J Bone Joint Surg (Am) 73:1555-1560, 1991

28. Geisler FH, Dorsey FC, Coleman WP: Recovery of motor function after spinal-cord injury--a randomized, placebo-controlled trial with GM-1 ganglioside. N Engl J Med 324:1829-1939, 1991 
29. Gillingham J: Early management of spinal cord trauma. J Neurosurg 44:766-767, 1976 (Letter) 30. Guha A, Tator CH, Endrenyi L, et al: Decompression of the spinal cord improves recovery after acute experimental spinal cord compression injury. Paraplegia 25:324-339, 1987

31. Guttmann L: Spinal Cord Injuries. Comprehensive Management and Research, ed 2. Oxford: Blackwell, 1976

32. Harris P, Karmi MZ, McClemont E, et al: The prognosis of patients sustaining severe cervical spine injury (C2-C7 inclusive). Paraplegia 18:324-330, 1980

33. Kobrine AI, Evans DE, Rizzoli HV: Correlation of spinal cord blood flow and function in experimental compression. Surg Neurol 10:54-59, 1978

34. Larson SJ, Holst RA, Hemmy DC, et al: Lateral extracavitary approach to traumatic lesions of the thoracic and lumbar spine. J Neurosurg 45:628-637, 1976

35. Levi L, Wolf A, Belzberg H: Hemodynamic parameters in patients with acute cervical cord trauma: description, intervention, and prediction of outcome. Neurosurgery 33:1007-1017, 1993

36. Maiman DJ, Larson SJ, Benzel EC: Neurological improvement associated with late decompression of the thoracolumbar spinal cord. Neurosurgery 14:302-307, 1984

37. Marshall LF, Knowlton S, Garfin SR, et al: Deterioration following spinal cord injury. A multicenter study. J Neurosurg 66:400-404, 1987

38. Maynard F, Reynolds GG, Fountain S, et al: Neurological prognosis after traumatic quadriplegia. Three year experience of California Regional Spinal Cord Injury Care System. J Neurosurg 50: $611-616,1979$

39. Nystrom B, Berglund JE: Spinal cord restitution following compression injuries in rats. Acta Neurol Scand 78: 467-472, 1988

40. Otani K, Abe H, Kadoya S, et al: Beneficial effect of methylprednisolone sodium succinate in the treatment of acute spinal cord injury. Sekitsui Sekizui J 7:633-647, 1994

41. Stover SL, DeLisa JA, Whiteneck GG: Spinal Cord Injury. Clinical Outcomes From the Model Systems. Gaithersburg, MD: Aspen, 1995

42. Tarlov IM: Spinal cord compression studies. III. Time limits for recovery after gradual compression in dogs. Arch Neurol Psychiatry 71:588-597, 1954

43. Tarlov IM, Klinger H: Spinal cord compression studies. II. Time limits for recovery after acute compression in dogs. Arch Neurol Psychiatry 71:271-290, 1954

44. Tator CH: Epidemiology and general characteristics of the spinal cord injury patient, in Benzel EC, Tator CH (eds): Contemporary Management of Spinal Cord Injury. Neurosurgical Topics. Park Ridge, Ill: American Association of Neurological Surgeons, 1995, pp 9-13

45. Tator CH, Duncan EG, Edmonds VE, et al: Comparison of surgical and conservative management in 208 patients with acute spinal cord injury. Can J Neurol Sci 14:60-69, 1987 
46. Tator CH, Duncan EG, Edmonds VE, et al: Neurological recovery, mortality and length of stay after acute spinal cord injury associated with changes in management. Paraplegia 33:254-262, 1995

47. Tator $\mathrm{CH}$, Fehlings MG: Review of the secondary injury theory of acute spinal cord trauma with emphasis on vascular mechanisms. J Neurosurg 75:15-26, 1991

48. Tator CH, Rowed DW, Schwartz ML, et al: Management of acute spinal cord injuries. Can J Surg 27:289-293, 296, 1984

49. Vaccaro AR, Daugherty RJ, Sheehan TP, et al: Neurologic outcome of early versus late surgery for cervical spinal cord injury. Spine 22:2609-2613, 1997

50. Vale FL, Burns J, Jackson AB, et al: Combined medical and surgical treatment after acute spinal cord injury: results of a prospective pilot study to assess the merits of aggressive medical resuscitation and blood pressure management. J Neurosurg 87:239-246, 1997

51. Wagner FC Jr, Chehrazi B: Early decompression and neurological outcome in acute cervical spinal cord injuries. J Neurosurg 56:699-705, 1982

52. Waters RL, Adkins RH, Yakura JS, et al: Effect of surgery on motor recovery following traumatic spinal cord injury. Spinal Cord 34:188-192, 1996

53. Weinshel SS, Maiman DJ, Baek P, et al: Neurologic recovery in quadriplegia following operative treatment. J Spinal Disord 3:244-249, 1990

54. Wiberg J, Hauge HN: Neurological outcome after surgery for thoracic and lumbar spine injuries. Acta Neurochir 91:106-112, 1988

55. Wilberger JE: Diagnosis and management of spinal cord trauma. J Neurotrauma 8 (Suppl 1):S21-S30, 1991

Manuscript received November 24, 1998.

Accepted in final form December 22, 1998.

Funding for this project was provided by the Joint Section of Neurotrauma and Critical Care and the Joint Section of Disorders of the Spine and Peripheral Nerves of the AANS and CNS. Dr. Fehlings is the recipient of a Career Scientist Award from the Ontairo Ministry of Health.

Address reprint requests to: Charles H. Tator, M.D., Division of Neurosurgery, The Toronto Hospital, Western Division, 399 Bathurst Street, McLaughlin Pavilion 2-435, Toronto, Ontario, M5T 2S8, Canada. email: ctator@torhosp.toronto.on.ca. 